\title{
MEMÓRIAS DE DIRETORES: ENTRE PRÁTICAS E HISTÓRIAS DO COTIDIANO ESCOLAR
}

\author{
João Pedro Pezzato* \\ Joyce Mary Adam de Paula e Silva* \\ Magali de Fátima Dias Borges** \\ Maria Isabel Nogueira Tuppy ${ }^{* * *+}$
}

\begin{abstract}
RESUMO
O presente artigo consiste no registro de memórias de um diretor e de uma diretora que atuaram em escolas públicas de Minas Gerais, e na análise de suas narrativas. O objetivo foi captar suas representações sobre as práticas administrativas e pedagógicas rememoradas dos anos de exercício profissional (1960 a 1990). Com a metodologia da história oral, nossa investigação buscou construir uma interpretação a respeito de atitudes, posturas e práticas enraizadas nos rituais da escola contemporânea. Pudemos observar que no período estudado havia uma política extremamente centralizada, cujas diretrizes eram difundidas pelos órgãos centrais da administração burocrática. $O$ trabalho de gestão das unidades escolares era pautado, principalmente, pelo controle do cumprimento das normas estabelecidas pela política pública de educação.
\end{abstract}

PALAVRAS-CHAVE: Memória. Política pedagógica. Práticas escolares.

* Doutor em Educação e professor da disciplina Prática de Ensino de Geografia do curso de Geografia da UNESP- Rio Claro.

** Doutora em Educação e professora da disciplina Políticas Públicas do curso de Pedagogia da UNESP- Rio Claro.

${ }^{* * *}$ Mestre em Educação, diretora e professora da rede pública de municípios do Sul de Minas Gerais.

${ }^{* * *}$ Doutora em Educação e professora do curso de Pedagogia da UNESP- Rio Claro. 


\begin{abstract}
The register of the memories of directors of Minas Gerais, their histories and practices are the present research. The subjects are two former directors one from a public state school and the other from a city public school. We thought about their administratives and pedagogical practices, and we look forward to contribute with new forward to contribute with new improvements regarding the work at school. We brought some memories of the day by day of work of the former directors for they are representations of the live reality during the school management from 60's till 90's. The methodology of verbal history completed the narratives of personal and professional live of the subjects of the researche. By covering this way of inquiring we followed the considered passge to build an interpretation regarding the attitudes and practices long used on the rituals of the contemporany school.
\end{abstract}

KEYWORDS: Memory. Political-pedagogical. School practices.

\title{
Introdução: notas a respeito dos sujeitos da memória
}

A presente pesquisa procura registrar algumas memórias de um diretor e de uma diretora que atuaram em duas escolas públicas de um município do sul do estado de Minas Gerais. O diretor entrevistado nasceu em 1920, no mesmo município em que trabalhou até obter sua aposentadoria. Estudou o Ensino Fundamental em Petrópolis, o Médio e o Superior no Rio de Janeiro, formando-se em Medicina. Antes de dirigir a escola foi professor de Ciências, mas por pouco tempo. Assumiu logo a função de diretor em 1965 e nesta função permaneceu até 1990, quando se aposentou no cargo, após 25 anos de trabalho. A diretora entrevistada também nasceu no município em questão, no ano de 1939, e realizou toda sua escolarização formal no Sul do estado de Minas Gerais. O Ensino Fundamental foi realizado no município em que nasceu, o Ensino Médio em Campanha e o Superior em Três

Educ. e Filos., Uberlândia, v. 21, n. 41, p. 135-154, jan./jun. 2007. 
Corações. Trabalhou como professora durante sete anos, entre 1959 a 1965, vindo, neste mesmo ano, a assumir a direção, e permaneceu no cargo até a sua aposentadoria em 1998. A partir daí desvinculou-se da Educação e passou a administrar o hotel da família.

No ano de 2005, foram registrados os depoimentos de José Paulo e de Gabriela com o intuito de analisar algumas das representações dos diretores a respeito das práticas administrativas e pedagógicas adotadas nos anos de atuação profissional. Cabe observar que os nomes dos entrevistados e das escolas envolvidas são fictícios.

O espaço vivido pelos diretores: de quais lugares surgem as memórias

O município onde estão localizadas as escolas em que nossos entrevistados atuaram é uma pequena e pacata cidade do interior de Minas Gerais que conta com um território de $323.32 \mathrm{~km}^{2}$ e, segundo dados do Instituto Brasileiro de Geografia e Estatística (IBGE), possuía, no ano de 2001, 12.545 habitantes. Atualmente, o município conta com uma economia diversificada, compreendendo atividades agrícolas, industriais e de prestação de serviços, mas as primeiras têm destaque com a produções permanentes (café e frutas cítricas) e temporárias (cana-de-açúcar, arroz, batata e mandioca).

Tendo recebido diversos nomes no decorrer de sua história, o município chegou a ser considerado a "Atenas Sul Mineira", pois contava com estabelecimentos de ensino de destaque. Uma escola de Ensino Médio, "o colégio", uma escola de formação de professores, "a Escola Normal Feminina", uma escola técnica "a Escola de Agricultura" e uma "Escola de Ensino Superior", com cursos de Farmácia e Odontologia. Nos anos de criação e início de funcionamento, todos estabelecimentos de prestígio. Hoje o município conta com 19 instituições educacionais, cerca de 2.300 alunos matriculados no Ensino Fundamental e perto de 500 no Ensino Médio.

A Escola Estadual Giotto di Bondone foi a unidade em que a professora Gabriela trabalhou como diretora por 24 anos, até se 
aposentar. Hoje a instituição atende em torno de 400 alunos do Ensino Fundamental das séries iniciais e Educação Infantil. Funcionou em diversos locais até que em 1989 o governo estadual construiu seu prédio próprio. Em 1998, a escola foi municipalizada.

O médico pediatra José Paulo trabalhou como diretor da Escola Estadual Jean Colombe, considerada uma escola de grande porte, na atualidade, pois atende aproximadamente 1.000 alunos, matriculados nas séries finais do Ensino Fundamental, no Ensino Médio e nas salas de Educação de Jovens e Adultos.

\section{Aspectos relativos aos procedimentos e algumas perspectivas de registro}

Considerando o tema e os objetivos propostos, a investigação adotou uma metodologia de pesquisa qualitativa e, nesse contexto, foram empregados métodos e técnicas da história oral, principalmente na perspectiva das contribuições de Paul Thompson (1992).

Por meio de entrevistas semi-estruturadas fizemos a gravação dos depoimentos dos entrevistados. Tomamos o conceito de depoimento com o sentido que lhe atribui Queiroz (1988). Diferente da história de vida, nos depoimentos são coletadas informações que só interessam ao pesquisador, ou seja, aqueles conhecimentos que estejam diretamente inseridos nos objetivos do trabalho. Embora a história de vida encerre um conjunto de depoimentos, há grandes diferenças entre ambos (QUEIROZ, 1988, p. 22). O foco principal da investigação em questão diz respeito às representações dos diretores sobre as práticas administrativas e pedagógicas vividas durante os anos de trabalho como gestores em escolas públicas do interior de Minas Gerais.

Para análise das representações sociais, a partir da análise da memória coletiva, utilizamos as reflexões de Maurice Halbwachs (1990). Ao analisar "os quadros sociais da memória", o autor considera que a memória é produto de um processo de construção social, cuja lembrança compõe representações que, muitas vezes, repousam em depoimentos e racionalizações: “[...] a lembrança é

Educ. e Filos., Uberlândia, v. 21, n. 41, p. 135-154, jan./jun. 2007. 
em larga medida uma reconstrução do passado com a ajuda de dados emprestados do presente, e, além disso, preparada por outras reconstruções feitas em épocas anteriores e de onde a imagem de outrora se manifesta já bem alterada" (p. 71).

Como aponta Halbwachs (1990), o registro da memória coletiva permite a produção de uma determinada visão do passado, pois a memória coletiva "é uma corrente de pensamento contínuo, de uma continuidade que nada tem de artificial, já que retém do passado somente aquilo que ainda está vivo ou capaz de viver na consciência do grupo que a mantém" (p. 81-82).

Segundo Meihy, (1996) a história oral é sempre uma história do tempo presente e, por esse motivo, é também denominada como história viva.

\section{Práticas pedagógicas e administrativas no contexto das políticas públicas}

Entre as décadas de 1960 a 1990 diversos acontecimentos se fizeram presentes no cenário educacional e um dos aspectos mais relevantes diz respeito à gestão democrática do ensino. Esta expressão que ficou estabelecida na nova LDB de 1996, refere-se a diferentes aspectos do processo educacional, com ênfase no envolvimento e participação de todos os atores da escola nesse processo. Questões como a constituição dos Conselhos de Escola e a construção da proposta pedagógica com a participação de professores, alunos, pais e comunidade são pontos centrais na questão da gestão democrática do ensino e que interferem significativamente nas práticas pedagógicas que são estabelecidas.

Quanto à gestão da escola, Paro (1986) aponta o caráter conservador que prevaleceu nas teorias da administração educacional produzidas no Brasil até a década de 1980. Em seus primórdios, por influência de teóricos de outros países, a produção intelectual em administração escolar no Brasil defendia a racionalização dos procedimentos administrativos nas instituições educacionais, visto que a escola tratava-se de uma empresa como outra qualquer, como afirmava Quirino Ribeiro (SILVA JR., 1993, p. 62): 
A escola é uma grande empresa enquanto visa atender clientela de milhões; reúne grupos de trabalhadores que somam centenas de milhares; exige financiamentos astronômicos; exige 'produção em massa', 'alta produtividade' para atender às mais variadas exigências do 'mercado' social, com o qual tem irrevogáveis compromissos de fornecimento, a tempo, à hora, em quantidades e qualidades que exigem técnicas aperfeiçoadas e complexas.

No entanto, concomitante a essa corrente, Anísio Teixeira vem recuperar uma visão mais crítica da administração da educação, ao afirmar que somente o educador ou o professor pode fazer administração educacional (SILVA JR., 1993), abrindo caminho para que outros educadores desenvolvessem estudos sobre esse tema de uma perspectiva mais crítica.

A discussão que se processou a respeito da administração escolar no Brasil girou principalmente em torno da dicotomia entre saber técnico e visão política porque os pioneiros dos estudos de administração escolar no Brasil adotaram os preceitos dos estudos de administração escolar norte-americanos, nos quais administração escolar e administração empresarial se confundiam. Assim, a adoção da racionalização do trabalho presente nas indústrias era considerada como o modelo mais adequado a ser implantado nas escolas.

Em finais da década de 1980 e de 1990, os estudos sobre administração escolar voltaram-se para a denúncia do caráter alienante da produção teórica na área trazendo uma leitura crítica e politizada sobre o tema. Tais estudos refletiram sobre a importância de a administração escolar se voltar para as peculiaridades das instituições educacionais recuperando sua função pedagógica e não meramente gerencial. Além disso, ressaltaram o aspecto político da educação como reprodutora de ideologia e como instrumento de superação de desigualdades sociais.

Outros estudos mostraram os aspectos burocráticos e a impregnação dos métodos da administração empresarial na prática

Educ. e Filos., Uberlândia, v. 21, n. 41, p. 135-154, jan./jun. 2007. 
da gestão escolar. Mendonça (2000), por exemplo, afirma que o Estado brasileiro desenvolveu uma burocracia com características peculiares, em que se destaca mais um caráter patrimonialista, com o aparelhamento racional das estruturas do Estado. O sistema educacional brasileiro, segundo esse autor, traz em sua organização traços muito fortes dessas características burocráticas e elas permanecem até hoje.

Fazendo uma análise dos elementos constitutivos do aparato administrativo de prestação de serviços das instituições, Weber (1982) afirma:

A estrutura burocrática vai de mãos dadas com a concentração dos meios materiais de administração nas mãos do senhor. Essa concentração ocorre, por exemplo, de modo bem conhecido e típico, no desenvolvimento das grandes empresas capitalistas, que encontram nesse processo suas características essenciais. Um processo correspondente ocorre nas organizações públicas (p. 257).

O sistema educacional brasileiro tem sido caracterizado por um processo de gestão burocrática que envolve a atribuição de competência conferida pelo diploma, e este como um pré-requisito para ocupação de cargos, princípios norteados pela hierarquia de postos e níveis de autoridade firmemente ordenados em funções de mando, obediência e supervisão.

O parcelamento de diferentes etapas de execução de tarefas, ou seja, a adoção de um sistema fragmentado de produção, denominado de sistema de produção taylorista, e a adoção da burocracia, implicando a divisão do trabalho, as especializações de espaços, a hierarquização de lugares e de funções, constituem modelos de gestão que imperaram pelo menos até finais da década de 1980, quando começaram a surgir questionamentos em termos de políticas públicas no âmbito da gestão escolar. Tais questionamentos resultaram de um novo contexto histórico vivenciado pelo país e foi, também, fruto de toda uma produção teórica e da mobilização de alguns setores da sociedade que 
denunciavam a inadequação dos modelos de gestão escolar adotados até então.

A gestão democrática, ao contrário das características de gestão apontadas acima, opõe-se aos modelos tayloristas e burocráticos na medida em que pressupõe a participação dos envolvidos no processo educacional em todas as etapas, desde a concepção de diretrizes de políticas educacionais, passando pelo planejamento e metas educacionais, até as medidas de implementação e avaliação de propostas (MENDONÇA, 2000).

A síntese aqui apresentada ilustra o caráter burocrático de que se revestiam a administração escolar e a gestão da educação no período em que os depoentes exerceram a função administrativa em suas escolas. Trata-se de um caráter eminentemente centralizador, nos quais as decisões "vinham de cima" e os depoimentos dos dois entrevistados corroboram, com pequenas diferenças de nuanças, esta tendência das antigas teorias da administração educacional que prevaleciam no Brasil.

\section{As práticas pedagógicas e administrativas rememoradas pelos depoentes}

O Plano Pedagógico da Escola é uma nomenclatura nova que não faz parte das rememorações dos depoentes. Na memória dos diretores o termo "plano" se refere a "plano de aula" ou "planejamento" de momentos cívicos na escola. Atualmente é atribuído ao projeto pedagógico um sentido que não possuía anteriormente. É um documento obrigatório dentro de todos os estabelecimentos de ensino e deve expressar os objetivos educacionais que, por sua vez, devem ser definidos coletivamente, ao menos no que diz respeito ao discurso oficial.

Em vez de falarem em Plano Pedagógico, os entrevistados referem-se ao Regimento Escolar. Este documento foi rememorado pelos depoentes como algo "sagrado", que "vinha" da "Delegacia de Ensino" e suas normas deveriam ser fielmente cumpridas.

Atualmente o Regimento Escolar e o Plano Pedagógico são considerados documentos básicos que devem ser elaborados pela

Educ. e Filos., Uberlândia, v. 21, n. 41, p. 135-154, jan./jun. 2007. 
escola, discutidos por todos envolvidos, para posteriormente ser homologado pelos órgãos superiores que legalizam as práticas das instituições vinculadas a determinados sistemas de ensino e, logicamente, nesta homologação, está circunscrito implicitamente o poder de determinação ou de veto.

$\mathrm{Na}$ ausência de discurso sobre o Projeto Pedagógico, os dois depoentes apontaram diferentes perspectivas a respeito da elaboração do Regimento Escolar. Para o diretor José Paulo, o documento era elaborado pela equipe administrativa e pedagógica da escola em conjunto com os supervisores e seguindo determinada orientação. Para Gabriela, ele vinha pronto da instância administrativa superior para ser adotado pela escola. Neste sentido, registramos os seguintes relatos:

Existia Regimento, quem fazia eram os diretores, supervisores e orientadores, vinha uma orientação da Delegacia Regional de Ensino $27^{\mathrm{a}}$ de Varginha (José Paulo, abril de 2005).

O Regimento vinha prontinho, só preenchia e mandava para a Delegacia para eles aprovarem. Mas era feito por eles (Gabriela, abril de 2005).

Mesmo sob a perspectiva de José Paulo, que admite certa flexibilidade na elaboração do Regimento Escolar, há uma profunda vinculação à sua formatação exógena e centralizada, pois a responsabilidade de sua elaboração ficava a cargo de um pequeno grupo dirigente.

No que diz respeito ao cumprimento das determinações contidas no Regimento, perguntamos: Quem controlava o cumprimento do Regimento? Todas as regras eram cumpridas? $\mathrm{O}$ que acontecia se alguma regra não fosse cumprida? E, assim, obtivemos as seguintes afirmações:

Não havia nenhuma regra (não cumprida). Todas que constavam eram seguidas com orientação da Delegacia de Ensino. Todas as normas eram cumpridas (José Paulo, abril de 2005). 
Devia haver regras não cumpridas, porque era coisa feita para todas as escolas da Delegacia. Ah! Eu não me lembro bem das normas, mas podia ter alguma coisa que não fosse cumprido, porque aquilo era feito para escola com crianças de situação financeira boa, crianças que não era ... então isto conta muito, né? Eu acho que conta muito, porque não podia exigir das minhas crianças e as crianças de outros grupos. Eu acho, não me lembro (Gabriela, abril 2005).

Pode-se observar, a partir dos depoimentos, uma postura diferenciada entre os dois entrevistados. Enquanto José Paulo percebe o conjunto de normas como algo definitivo e intransigente, Gabriela levanta, mesmo que fortuitamente, a questão da impossibilidade de uniformização das condutas para grupos sociais distintos. Em seus argumentos podem ser percebidos elementos que coincidem com os pressupostos daqueles que lutam pela autonomia da instituição escolar.

Quando perguntados pela elaboração ou pelo desenvolvimento de planos, os diretores focaram os planos de ensino, já que a discussão sobre Plano Pedagógico da instituição, tal qual definido atualmente, era incipiente até a aposentadoria dos depoentes. Segundo suas memórias:

Os planos e as aulas eram elaborados pelos professores e supervisores. Porém os professores e supervisores faziam um plano, mandava para a Delegacia e a Delegacia aprovava e seguia aquilo. As ações previstas neste plano eram os dias das mães, datas públicas da cidade (José Paulo, abril de 2005).

Nas rememorações da diretora Gabriela:

Eu não me lembro... mas acho que não existia Plano da Escola. Me parece que havia uma semana da comunidade. Era uma festa bonita e havia também a semana da alimentação, mas eu não sei se foi nessa época. Em 1980 tinha. Festeja-se o dia da cidade, semana da pátria, sempre havia comemoração,

Educ. e Filos., Uberlândia, v. 21, n. 41, p. 135-154, jan./jun. 2007. 
preparava-se desfile, a gente fazia carro alegórico, era bem planejado sim (Gabriela, abril de 2005).

As rememorações acima demonstram uma maior preocupação com o cumprimento das atividades (e tarefas) solicitadas pelos órgãos de controle e difusão da política pública oficial do que para com os problemas internos da instituição. A presença de um órgão centralizador da administração foi comumente presente nas rememorações dos depoentes. Tal fato nos remete ao pensamento de Weber, quando trata da burocracia moderna e dos elementos que constituem a "autoridade burocrática":

1. As atividades regulares necessárias aos objetivos da estrutura governada burocraticamente são distribuídas de forma fixa como deveres oficiais;

2. A autoridade de dar as ordens necessárias à execução desses deveres oficiais se distribui de forma estável, sendo rigorosamente delimitada pelas normas relacionadas com os meios de coerção, físicos, sacerdotais ou outros, que possam ser colocados à disposição dos funcionários ou autoridades; 3. Tornam-se medidas metódicas para a realização regular e contínua desses deveres e para a execução dos direitos correspondentes; somente as pessoas que têm qualificação previstas por um regulamento geral são empregada (WEBER, p. 229, 1982).

A construção de um Projeto Pedagógico, compartilhado coletivamente, que oferecesse sentido às práticas e reconstruísse de forma dinâmica e histórica a identidade institucional - e, por isso, também um projeto político - não faz parte da memória dos depoentes.

No que diz respeito ao currículo, as atuais discussões acadêmicas têm apontado o conceito como algo relativo aos saberes construídos socialmente, no qual estão inseridas questões de identidade e de poder ou, ainda, um lugar, um espaço, um território em que são explicitadas relações de poder. No entanto, o currículo 
foi rememorado como uma palavra de sentido pontual e técnica. Os diretores, Gabriela e José Paulo, mencionaram o termo como "grade curricular" e lista de disciplinas. E algumas das disciplinas foram apontadas como merecedoras de maior destaque que outras.

Falando a respeito da importância das diferentes disciplinas o diretor apontou:

[...] todos são importantes. Tanto faz o desenho quanto o inglês. No meu tempo de diretor, tiravam uma cadeira para pôr outra, a delegacia mandou tirar, depois eles viram que não dava certo e mandou voltar. Tem gente que acha que é o português, outros acham que é a matemática, mas eu acho que o estudo tem que ter um conhecimento geral de todas as matérias, né...? Tem que ter um conhecimento geral (José Paulo, abril de 2005).

Na fala da diretora Gabriela a seleção de conteúdos vinha elaborada pela Secretaria, como mostra seu depoimento:

[...] Já vinha pronta a grade curricular. A professora fazia aquilo. Havia um programa, vinha um programa de ensino por série e ali a professora fazia o plano dela, cada um fazia o seu. Este programa vinha de Belo Horizonte. Vinha um programa por matéria. Me parece que vinha divididinho em $1^{\circ}, 2^{\circ}, 3^{\circ}$ e $4^{\circ}$ bimestre (Gabriela, abril de 2005).

A diretora associa o currículo à "grade curricular" estruturada conforme determinação de um órgão central, e que, na sua concepção, apresenta uma hierarquia de disciplinas, conforme aponta:

Olha, por meus alunos lá, eu achava que o mais importante era o Português e a Matemática, porque eles não iam trabalhar com Ciências, com Geografia, com História. Mas o que eu achava importante mesmo, e que devia importar e pedir, era o Português e a Matemática. Tinham que falar direitinho,

Educ. e Filos., Uberlândia, v. 21, n. 41, p. 135-154, jan./jun. 2007. 
escrever, qualquer coisa assim. Por mais simples que fossem, eles teriam que saber bem. E a Matemática para a vida deles. Eles tinham que fazer as operações. Tinham que saber calcular. O que eu achava mais importante era isso (Gabriela, abril de 2005).

Para a diretora Gabriela o que mais interessava era ensinar a ler, a escrever e a calcular. Na sua concepção a Ciência, a História e a Geografia e outras áreas do conhecimento ficariam em plano inferior ao da Língua Materna e da Matemática.

Contudo, independente da divergência em relação à ênfase ou não para determinadas disciplinas, estão isentas de ambas memórias a interpretação do currículo como instância de poder e legitimação das desigualdades sociais. O conteúdo, para ambos, aparece como algo fundamentalmente instrumental.

Em alguns momentos de suas rememorações a diretora Gabriela aponta os problemas socioeconômicos dos alunos de sua escola, ou tece considerações a respeito de suas dificuldades para freqüentarem a escola de educação formal. Quando questionada acerca da existência de recursos destinados para o transporte de alunos, já que muitos deles residiam em área rural e a escola estava localizada no perímetro urbano, a diretora assim se manifestou:

[...] Os alunos da Zona Rural, eles vinham, os coitadinhos saiam de lá, por exemplo, lá da Boa Vista no caminhão leiteiro, traziam marmita e deixavam a marmita na minha casa, almoçavam ali pra dez horas. Eles iam para a escola. A gente dava merenda, um pouco da merenda que sobrava do turno da manhã e dava pra eles. Eles tomavam merenda também na hora de ir embora. Tinha uns vinte e tantos alunos que vinham da Zona Rural, vinham também alunos da Barra, mas esses vinham a pé (Gabriela, abril de 2005).

Conquanto admita a dificuldade que enfrentavam os alunos da área rural, ou mesmo de outros em situação socioeconômica precária, analisa o fato segundo uma perspectiva pontual e isolada 
das políticas públicas, à medida que as soluções propostas tinham um caráter assistencial.

Solicitamos que os diretores apontassem algumas diferenças entre a escola "de hoje" e a escola "do passado". O diretor aponta, de um lado, certo otimismo no que se refere aos recursos:

Hoje a escola está bem melhor. Eu não tenho acompanhado, não tenho filho que estuda no colégio. Mas a assistência tem sido muito maior! A escola de hoje é ajudada pela prefeitura. Tudo ajuda. Hoje é tudo mais fácil, a televisão, a eletrônica e o computador. Antes não tinha nada disso, o aluno tinha que prender a cabeça no giz. A escola melhorou muito. A assistência tem sido maior. Antes tinha muitos colégios particulares, hoje há mais escolas públicas (José Paulo, abril de 2005).

mas, de outro lado, aponta a queda do conhecimento do aluno e as mudanças das relações entre professores e alunos:

Antes o aluno saia sabendo, hoje sai de qualquer jeito, não pode tomar bomba, vai passando de qualquer maneira, é o que eu vejo falar. Tinha mais disciplina, os alunos tinham mais respeito. É porque hoje a gente tem a televisão, tudo aparelho automático, né? O aluno saía dos quatro anos primários sabendo bem ler e escrever e muito bem interpretar. Hoje sai do ginásio, mal escreve o nome, todos não, toda regra tem sua exceção (José Paulo, abril de 2005).

Sob uma perspectiva simplista, admite que o avanço tecnológico impinge certa vantagem à escola, mas este mesmo avanço também seria responsável por um "baixo" nível de aprendizado.

A diretora Gabriela afirma estar um pouco distante dos acontecimentos relativos ao universo escolar, embora apresente considerações que são também recorrentes nas observações de professores que estão na ativa:

Educ. e Filos., Uberlândia, v. 21, n. 41, p. 135-154, jan./jun. 2007 
Atualmente estou meio por fora da escola de hoje. Mas o que eu ouço falar é que não há mais reprovação. Eu estou vendo o pessoal que eu tenho lidado aqui. Eles fizeram até o científico como que chama agora? Tem funcionária aqui no hotel que já fez o segundo grau, científico, ensino médio e escreve muito mal. Hoje eles estão aprovando assim sem fazer um (apertar) um pouquinho. O mínimo exigido por eles está muito pouco, muito mínimo. Precisava exigir mais. Eu acho que as crianças estão muito livres. Esse negócio do Estatuto da Criança e do Adolescente, ...estão com as asas muito grande, tem que podar um pouquinho (Gabriela, abril de 2005)

Ambas posições denotam uma visão fragmentada do universo educacional, na qual não se coloca a dimensão das diferenças entre a cultura elitizada (ou alta cultura), e valorizada pela escola, e aquela trazida pelas camadas populares que o processo de universalização do ensino levou para o interior das instituições escolares.

Como importante mudança no tratamento dos conteúdos escolares, Gabriela lembra de mudanças que ocorreram no ensino da Língua Materna. Antes o foco recaía, sobretudo, na "gramática funcional". Embora admita a importância da interpretação de texto, que hoje predomina no ensino da língua, deixa entrever certa preferência pelo antigo enfoque, quando admite um conhecimento mais profundo dos antigos alunos:

As crianças do passado sabiam muito mais, muito mais... Eu me lembro da época em que eu dei aula, a gente ensinava a gramática funcional. Eles faziam análise perfeita, faziam análise do jeito que a gente ensinava, eles entendiam muito bem. Agora uma coisa que acho importante e muito boa, que ocorre nos dias de hoje, é a interpretação de texto. Naquela época a gente não tinha isso. (Gabriela, abril de 2005).

O desempenho escolar foi rememorado como um processo restrito que envolvia a classificação. Os depoentes lembram das 
provas orais como uma das formas de avaliação adotadas. A validação do desempenho era efetuada por meio de provas bimestrais.

O desempenho escolar era realizado através de provas escritas, argüições. Os professores, os orientadores entravam na sala para verificar se estavam sendo cumprido. O diretor entrava para ver se o professor estava certo (José Paulo, abril de 2005).

Aqui, novamente, percebe-se a centralização do poder e, claramente, o papel supervisor de uma equipe dirigente, além, é claro, da visão de avaliação como produto exclusivo do desempenho do aluno. As observações acerca de avaliação processual e contextualizada passam a largo da memória do depoente.

Gabriela, por sua vez, lembra que o sistema de avaliação envolvia a aplicação bimestral de provas. Ao mesmo tempo em que a diretora mostra-se preocupada em atender as solicitações advindas dos órgãos centrais sem questionar, ela comenta uma experiência vivida na escola em que estudou e que buscou adotar na instituição em que trabalhou, pois poderia ser uma prática positiva para melhorar o desempenho dos estudantes, independente de ser uma regra institucionalmente adotada. Conforme relata:

O desenvolvimento escolar era por meio de provas. Este modo de proceder era bastante usado. Sugeria ao corpo docente aplicarem uma avaliação semanal. Não tinha nome de prova. Eles tinham um caderninho. Toda semana era feito um apanhado do que havia estudado, pois as crianças lá eram assim, a maioria saía da escola ia pra rua brincar o dia inteiro, outros iam trabalhar, faziam os deveres, correndo, correndo de qualquer jeito. Então para fixar mais eu falava para elas fazerem uma verificação no final de cada semana, de tudo que foi ensinado. E quando eu estudei, também a gente fazia isto. Então eu peguei técnica do colégio que eu estudei e

Educ. e Filos., Uberlândia, v. 21, n. 41, p. 135-154, jan./jun. 2007. 
passei para elas. Eu achava que isto ajudava muito. Mas o que contava mesmo na nota para a promoção era a prova. No início era só nota, mais tarde passou-se a uma porcentagem de freqüência. Não havia recuperação nem avanços escolares (Gabriela, abril de 2005).

Conquanto Gabriela apresente preocupação com o desempenho dos alunos, percebe-se a inexistência de práticas de discussão coletiva ou de busca de maior compreensão sobre o processo de avaliação. Sua preocupação não ultrapassa a própria experiência, retomando uma antiga prática registrada em suas memórias de aluna. Tal fato demonstra que os dados oferecidos pela vivência concreta da diretora não foram suficientes para mudar suas representações a respeito da avaliação e, portanto, não possibilitaram mudanças de práticas transformadoras no processo de avaliação realizado no cotidiano escolar.

\section{Considerações finais}

As representações dos dois diretores entrevistados mostram algumas confluências e, também, algumas diferenças. Mas o modo burocrático de gerenciamento impresso pela política educacional da época fica nítido nos depoimentos de ambos. Eles preocupavamse, sobretudo, em cumprir suas funções, segundo as designações legais, buscando atender aos regulamentos e às tarefas administrativas, em conformidade com as exigências dos superiores hierárquicos.

As práticas pedagógicas não eram objeto de questionamento, de discussão coletiva ou de reflexão, que aparecem hoje como passos fundamentais para o processo de construção de saberes docentes e de formação continuado do professor.

Inexistia um Projeto Pedagógico das escolas, ou seja, um projeto que contemplasse as especificidades de cada instituição escolar. Os objetivos eram traçados longe da escola e dos interesses e das necessidades de sua comunidade, tampouco tinha ela a possibilidade de participar da construção da identidade institucional. 
As representações dos diretores pretendem dar conta de uma escola organizada, disciplinada, em cujo espaço as aprendizagens se davam de maneira mais profunda. Mas elas demonstram, de fato, o poder de uma política educacional que impossibilitava o questionamento da organização vigente e que camuflava, sob o aparato de um referencial técnico e legal, as dicotomias existentes na sociedade e reproduzidas no interior das escolas.

Foi preciso um longo processo político para que novos referenciais fossem admitidos nas práticas pedagógicas e administrativas das instituições educacionais e parte do resultado desse processo pode ser identificado como os avanços da gestão colegiada e da construção dos Projetos Pedagógicos pelas próprias instituições, agora admitidos em Lei. Porém, ainda há muito a ser feito, principalmente se considerarmos que as representações sociais acabam por se constituir, ao longo dos tempos, como diretrizes de concepções e de práticas que fazem reproduzir o modus operandi sem questionamento ou resistência.

Talvez, por isso, muitas das representações aqui oferecidas pelos depoentes representem muito das práticas pedagógicas e administrativas ainda existentes. Contudo, consideramos que análises históricas podem contribuir para a discussão da vida cotidiana e podem, também, contribuir para que os sujeitos possam se tornar mais críticos das suas representações. Nesse sentido, mediante a possibilidade da crítica, acreditamos que os sujeitos envolvidos com o fenômeno educativo possam adotar práticas mais comprometidas e transformadoras do cotidiano escolar.

\section{Referências}

BRASIL. Lei de Diretrizes e Bases da Educação Nacional n 9394, de 20 de dezembro de 1996.

CUNHA, Luiz Antônio . Educação, Estado e democracia no Brasil. São Paulo: Cortez; Niterói: Editora da Universidade Federal Fluminense; Brasília: FLACSO do Brasil, 1991. (Coleção Biblioteca de Educação. Série1. Escola, v. 17).

Educ. e Filos., Uberlândia, v. 21, n. 41, p. 135-154, jan./jun. 2007 
FELIX, M. F. C. Administração escolar: um problema educativo ou empresarial. 4. ed. São Paulo: Cortez, 1989.

HALBWACHS, M. A memória coletiva. São Paulo: Vértice, 1990.

MEIHY, J. C. S. B. Manual de História Oral. São Paulo: Edições Loyola, 1996.

MENDONÇA, E. F. A Regra e o Jogo. Campinas: Unicamp, 2000.

PARO, Vitor Henrique. Administração Escolar: introdução crítica. São Paulo: Cortez; Autores Associados, 1986.

QUEIROZ, M. I. P. Relatos orais: do "indizível ao dizível". In: VON SIMSOM, Olga de M. (Org.). Experimentos com histórias de vida. São Paulo: Vértice; Revista dos Tribunais, 1988, p. 14-43.

QUEIROZ, M. I. P. Variações sobre a técnica de gravador no registro da informação viva. São Paulo: T.A Queiroz, 1991.

SILVA JUNIOR, C. A. A Escola Pública como Local de Trabalho. São Paulo: Cortez, 1993.

WEBER, M . Ensaios de Sociologia. 5. ed. Rio de Janeiro: Editora Guanabara, 1982 .

SÃO PAULO. Conselho Estadual de Educação. Indicação CEE n. 09/97. São Paulo, 1997.

SÃO PAULO. Secretaria da Educação. Decreto-lei n. 10.623, 26 de outubro de 1977. Estabelece o Regimento Comum das Escolas Estaduais de Primeiro Grau. Diário Oficial, São Paulo, v. 87, n. 206, 27 de out. 1977.

SÃO PAULO. Secretaria da Educação. Decreto-lei n. 11.625, de 23 de maio de 1978. Estabelece o Regimento Comum das Escolas 
Estaduais de Segundo Grau. Diário Oficial, São Paulo, v. 88, n. 95, 24 de maio de 1978.

Data de registro 20/07/06

Data de aceite 30/08/06

Educ. e Filos., Uberlândia, v. 21, n. 41, p. 135-154, jan./jun. 2007. 